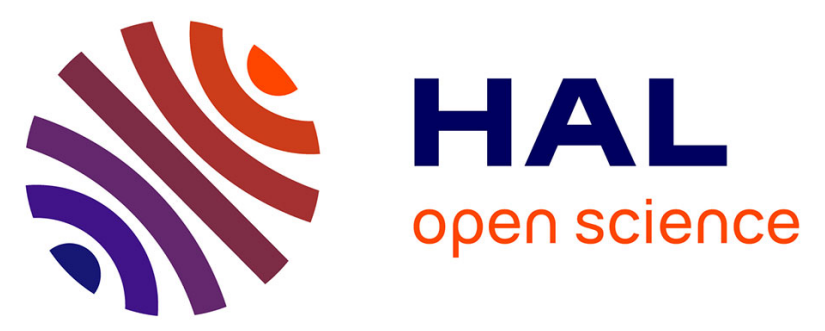

\title{
Can the Pediatric Logistic Organ Dysfunction (PELOD)-2 Score on Day 1 Be Used in Clinical Criteria for Sepsis in Children?
}

Francis Leclerc, Alain Duhamel, Valérie Deken, Bruno Grandbastien, Stéphane Leteurtre, D Biarent, R Cremer, D Dauger, M Dobrzynski, G Emeriaud, et al.

\section{To cite this version:}

Francis Leclerc, Alain Duhamel, Valérie Deken, Bruno Grandbastien, Stéphane Leteurtre, et al.. Can the Pediatric Logistic Organ Dysfunction (PELOD)-2 Score on Day 1 Be Used in Clinical Criteria for Sepsis in Children?. Pediatric Critical Care Medicine, 2017, 18 (8), pp. 758-763. 10.1097/PCC.0000000000001182 . hal-01943157

\section{HAL Id: hal-01943157 https://hal.science/hal-01943157}

Submitted on 3 Dec 2018

HAL is a multi-disciplinary open access archive for the deposit and dissemination of scientific research documents, whether they are published or not. The documents may come from teaching and research institutions in France or abroad, or from public or private research centers.
L'archive ouverte pluridisciplinaire HAL, est destinée au dépôt et à la diffusion de documents scientifiques de niveau recherche, publiés ou non, émanant des établissements d'enseignement et de recherche français ou étrangers, des laboratoires publics ou privés. 
LECLERC, Francis, DUHAMEL, Alain, DEKEN, Valérie, GRANDBASTIEN, Bruno, LETEURTRE, Stéphane, BIARENT, D, CREMER, R, DAUGER, D, DOBRZYNSKI, M, EMERIAUD, G, RENOLLEAU, S, ROQUE-GINESTE, M, STAMM, D, JAVOUHEY, Etienne, WROBLEWSKI, I, THIRIEZ, G, GROUPE FRANCOPHONE DE REANIMATION ET D'URGENCES PEDIATRIQUES GFRUP, 2017, Can the Pediatric Logistic Organ Dysfunction-2 Score on Day 1 Be Used in Clinical Criteria for Sepsis in Children?, Pediatric Critical Care Medicine, 18, 8, Lippincott Williams \& Wilkins, pp. 758-763, DOI: 10.1097/PCC.0000000000001182

CAN THE PELOD-2 SCORE ON DAY 1 BE USED IN CLINICAL CRITERIA FOR SEPSIS IN CHILDREN?

Francis Leclerc, MD, PhD 1,2, Alain Duhamel, $\mathrm{PhD}^{2,3}$, Valérie Deken ${ }^{2,3}$, Bruno Grandbastien, MD, PhD ${ }^{2,4}$ and Stéphane Leteurtre, MD, Phd ${ }^{1,2}$ on behalf of the Groupe Francophone de Réanimation et Urgences Pédiatriques (GFRUP) ${ }^{5}$

1: CHU Lille, Service de réanimation pédiatrique, F-59000 Lille, France

2: Univ. Lille, EA 2694 Santé publique, épidémiologie et qualité des soins, F-59000 Lille, France

3: CHU Lille, Département de biostatistiques, F-59000 Lille, France

4: CHU Lille, Service de gestion du risque infectieux, des vigilances et d'infectiologie (SGRIVI), F-59000 Lille, France

\section{${ }^{5}$ Collaborators :}

Authors belonging to Groupe VALIDscore of the GFRUP: D. Biarent (Bruxelles, Belgium), R. Cremer (Lille, France); S. Dauger (Robert Debré-Paris, France), M. Dobrzynski (Brest, France), G. Emeriaud (Grenoble, France), S. Renolleau (Trousseau-Paris, France), M. RoqueGineste (Toulouse, France), D. Stamm, E Javouhey (Lyon, France), and I. Wroblewski, G Thiriez (Besançon, France). 
Corresponding author : Pr Francis Leclerc, CHU Lille, Pediatric Intensive Care Unit, Hôpital Jeanne de Flandre, avenue Avinée, F-59000 Lille, France,

e-mail: fleclercchru@yahoo.fr,

Phone: +33320445982 ,

Fax: +333204446133

Pr Alain Duhamel: alain.duhamel@univ-lille2.fr

Miss Valérie Deken: vdeken.chr@gmail.com

Dr Bruno Grandbastion: bruno.grandbastien@chru-lille.fr

Pr Stéphane Leteurtre: stephane.leteurtre@chru-lille.fr

Keywords: sepsis, septic shock, multiple organ dysfunction, PELOD-2 score, children Copyright form disclosure: The authors have disclosed that they do not have any potential conflicts of interest. 
Abstract.

A recent task force has proposed the use of sequential organ failure assessment (SOFA) in clinical criteria for sepsis in adults.

OBJECTIVE. To evaluate the predictive validity for PICU mortality of the PELOD-2 and of a « quick » PELOD-2 on day 1 (d1PELOD-2 and d1qPELOD-2) in children admitted with suspected infection.

DESIGN, SETTINGS, PATIENTS. We analyzed the database used for the PELOD-2 development and validation. Only children with infection as the cause of primary disease at entry (defined by physician diagnosis) were enrolled. Children with hypotension-low systolic blood pressure (SBP) or low mean blood pressure (MBP) using age-adapted cutoffs-and lactatemia $>2 \mathrm{mmol} / \mathrm{L}$ were considered in shock. MEASUREMENTS AND MAIN RESULTS. We developed the d1qPELOD-2 including tachycardia, hypotension and altered mentation (Glasgow<11): one point for each variable (range: 0-3). Outcome was mortality at PICU discharge.

Discrimination (AUROC-95\% $\mathrm{Cl}$ ) and calibration (goodness of fit test) of the scores were studied.

This study included 862 children with suspected infection (median age: 12.3 months, mortality: $n=60,7.0 \%)$. AUC of the d1PELOD-2 score was $0.91(0.86-0.96)$ in children with suspected infection, $0.88(0.79-0.96)$ in those with low SBP and hyperlactatemia, and $0.91(0.85-0.97)$ in those with low MBP and hyperlactatemia; calibration $p$ value was $0.03,0.36$ and 0.49 , respectively. A d1PELOD-2 $\geq 8$ reflected an overall risk of mortality $\geq 9.3 \%$ in children with suspected infection.

AUC of the d1qPELOD-2 was $0.82(0.76-0.87)$ with SBP or MBP, calibration $p$ value was 0.89 and 0.72 , respectively. A score $\geq 2$ reflected a mortality risk $\geq 19.8 \%$ with 
SBP and $\geq 15.9 \%$ with MBP.

CONCLUSION. Among children admitted to PICU with suspected infection, d1PELOD-2 was highly predictive of PICU mortality suggesting its use to standardize definitions and diagnostic criteria of pediatric sepsis. Further studies are needed to determine the usefulness of the d1qPELOD-2 outside of the PICU. 
Sepsis is a leading cause of death in adults (1) as well as in children $(2,3)$. The sepsis syndrome is characterized by non-specific physiologic abnormalities that encompass a heterogeneous population, and, thus, remains difficult to define. Consensus criteria for pediatric sepsis that were proposed in 2005 to facilitate consistent enrollment across research studies (4) are widely adopted for use in clinical practice (5). However, published reports have demonstrated only moderate overlap of physician diagnosis of severe sepsis with consensus criteria, illustrating that many children diagnosed and treated for severe sepsis in clinical practice may have important physiologic and outcome differences from those studied in clinical trials $(2,6,7,8)$. Recently, a task force recommended, for adult patients, elimination of the terms sepsis syndrome, septicemia and severe sepsis and instead defined sepsis as « life threatening organ dysfunction due to a dysregulated host response to infection »(9). Seymour and colleagues, analyzing 1.3 million electronic health record encounters identified adults with suspected infection and observed that the predictive validity for in-hospital mortality of Sequential Organ Failure Assessment (SOFA) among ICU encounters was statistically greater than SIRS, which supports its use as a diagnostic criteria of sepsis. A simplified « quick » SOFA (qSOFA), including Glasgow Coma Scale, systolic blood pressure and respiratory rate had a good predictive validity for hospital mortality of patients outside the intensive care unit (ICU) (10).

The aim of this study was to evaluate the predictive validity for Pediatric ICU (PICU) mortality of the PEdiatric Logistic Organ Dysfunction-2 (PELOD-2) and of a « quick » PELOD-2 (qPELOD-2 including Glasgow Coma Scale, systolic or mean blood pressure and heart rate) both on day 1 in children admitted with suspected infection 
or septic shock in PICUs.

\section{METHODS}

We performed a secondary analysis of the database used for the development and validation of the PELOD-2 score (11), which included all consecutive children admitted between June 21, 2006, and October 31, 2007, into nine university-affiliated PICUs (eight in France and one in Belgium) that are members of the Groupe Francophone de Réanimation et Urgences Pédiatriques (GFRUP). Exclusion criteria were: age 18 years or older; premature at entry into PICU; pregnancy; total length of stay in PICU less than $4 \mathrm{~h}$; admission in a state of continuous cardiopulmonary resuscitation without achieving stable vital signs for at least $2 \mathrm{~h}$; transfer from another PICU; and admissions for scheduled procedures normally performed in other hospital locations.

\section{Ethical Considerations.}

The study and its database were declared safe and were approved by the French authorities (Commission Nationale de l'Informatique et des Libertés) on February 7, 2007. The study design was approved by the ethics committee of the Société de Réanimation de Langue Française on April 27, 2007. The requirement for consent was waived because the study was strictly observational.

Data management.

Data management, recording and quality control processes are detailed in the article by Leteurtre et al (11). In brief, patients were monitored until they died or were discharged from PICU. As for previously published severity and multiple organ dysfunction syndrome scores, the most abnormal value of each variable observed during day 1 was considered to calculate the PELOD-2 score on day 1 (d1PELOD-2). If a variable was not measured, we assumed that it was normal (i.e. the physician 
considered that the value of the variable was normal). Covariates and cutoffs were those of our previous publication (11).

For the current study, only children with infection as the cause of primary disease at entry (defined by physician diagnosis) were enrolled. Among them, those with hypotension - low systolic blood pressure (SBP) using age-adapted cutoffs of the PELOD (12) or low mean blood pressure (MBP) using age-adapted cutoffs of the PELOD-2 (11) — and hyperlactatemia (serum lactate level >2 mmol/L) were considered as having septic shock (9). Two other lactate thresholds were considered ( $>3$ and $>4 \mathrm{mmol} / \mathrm{L})$.

Also, similarly with what was proposed by the Third International Consensus Task Force $(10,13)$ we developed the quick PELOD-2 on day 1 (d1qPELOD-2) including tachycardia (instead of tachypnea, not collected in the PELOD-2 database) that has a higher predictive value in children (14)), hypotension (low SBP or MBP) and altered mentation (Glasgow < 11) (see $(11,12$ ) for cutoffs) with a point score of 1 assigned to each variable (range: 0-3) (Table 1). The PICU discharge status (death/survival) was used as the outcome dependent variable.

Statistical Analysis.

The results are expressed by median and interquartile ranges (IQR) for continuous variables and by frequencies and percentages for categorical variables. The comparisons of the d1PELOD-2 and d1qPELOD-2 scores between the two groups (dead/survivor) were performed by an unpaired Wilcoxon test. The discriminant power of the scores was estimated using the areas under receiver operating characteristic curve (AUC) with 95\% confidence intervals (CI) and an optimal cutoff was defined using the maximization of the Youden index; calibration was assessed using the Hosmer-Lemeshow chi-square test with a degree of freedom of 8 (a p 
value $>0.05$ indicates a good calibration). We addressed the optimism bias using a bootstrap resampling method. We used a logistic regression to investigate the relation between d1PELOD-2, d1qPELOD-2 and mortality. As no imputation of variables not measured (and considered as normal: see above) was performed we verified that mortality of children with variable not measured was very similar to that of children with normal values, and very dissimilar to that of children with abnormal values. Statistical analyses were performed using SAS software version 9.3 (SAS Institute, Cary, NC). A p value of less than 0.05 was considered statistically significant.

Results.

This study included 862 children with suspected infection among 3,669 patients from the original database (11) (two with incomplete data being excluded). Characteristics of the population are reported in Table 2. The mortality rate was $7.0 \%$ (60 deaths /862) close to the $6.0 \%$ of the whole population (222 deaths /3671). The median d1PELOD-2 was 3 (IQR: 1-5) in children with suspected infection who survived and $13(9-18)$ in those who died $(p=0.0001)$. A d1PELOD-2 $\geq 8$ reflected an overall risk of mortality of $9.3 \%$ or more in children with suspected infection. In children having a low SBP with hyperlactatemia $(n=69)$ the d1PELOD-2 was $7.5(5-11)$ in those who survived (66.7\%) and $17(13-20)$ in those who died $(33.3 \%)(p<0.0001)$. In those having a low MBP with hyperlactatemia $(n=88)$ the d1PELOD-2 was $7(5-10)$ in children who survived (69.43\%) and 16 (13-20) in those who died (30.7\%) $(p=0.0001)$. The odds ratio of death per unit of the d1PELOD-2 was $1.50(95 \% \mathrm{Cl}$ :1.39 - 1.63) in our population as a whole (table 3).

The AUC of the d1PELOD-2 score was $0.91(95 \% \mathrm{Cl}, 0.86-0.96)$ in children with suspected infection, $0.88(95 \% \mathrm{Cl}, 0.79-0.96)$ in those with low SBP and 
hyperlactatemia, and $0.91(95 \% \mathrm{Cl}, 0.85-0.97)$ in those with low MBP and hyperlactatemia; after correction for the optimism bias, the AUC (and 95\% $\mathrm{Cl}$ ) were strictly identical. The calibration $p$ values were equal to $0.03,0.36$ and 0.49 , respectively. Discrimination and calibration were not influenced by the lactate threshold considered $(2,3$, or $4 \mathrm{mmol} / \mathrm{L})$. When we considered three categories of age ( $<1$ year, 1 to 12 years and $>12$ years) the AUC of the d1PELOD-2 was 0.93 $(95 \% \mathrm{Cl}, 0.87-0.98)$ for children less than one year of age and $0.88(95 \% \mathrm{Cl}, 0.76-$ 0.99) in those between 1 to 12 years; the AUC could not be determined for children of more than 12 years of age because of the small sample size. Among nonsurvivors, $85.0 \%$ (sensitivity, Se) had 8 or more d1PELOD-2 points and $88.4 \%$ (specificity, Sp) of survivors had less than 8 d1PELOD-2 points; among patients with a score of 8 or more, $35.4 \%$ died (positive predictive value, Ppv), while $98.8 \%$ of those having a score less than 8 survived (negative predictive value, Npv). Among patients with low SBP and lactatemia $>2 \mathrm{mmol} / \mathrm{L}, 91.3 \%$ (Se) who died had 11 or more d1PELOD-2 points and 69.6\% (Sp) of those who survived had less than 11 d1PELOD-2 points (Ppv: 60.0\%; Npv: 94.1\%). Among patients with low MBP and lactatemia $>2 \mathrm{mmol} / \mathrm{L}$ who died, 92.6\% (Se) had 11 or more d1PELOD-2 points and $75.4 \%$ (Sp) of those who survived had less than 11 d1PELOD-2 points (Ppv: 62.5\%; Npv: 95.8\%). Mortality of children with variables not measured was very dissimilar to those with abnormal values (all $p$ values were $<0.001$, except for MAP but this is due to the small number of patients $(n=21)$ with variable not measured); for each variable included in the PELOD-2 score, when comparing mortality of children with variables not measured and that of children with normal values for this variable, after adjustment for the d1PELOD-2 (computed without the variable), we did not found any significant differences in mortality between the two groups, except for pupillary 
reaction and ventilation but there were less than $5 \%$ of these variables not measured.

The median d1qPELOD-2 were the followings: 2 (IQR: 1-2 with SBP and 1.5-3 with MBP) in children who died and 1 (IQR: $0-1)$ in those who survived $(p<0.0001)$. Odds ratio of death per unit of the d1qPELOD-2 range from $4.93(95 \% \mathrm{Cl}: 3.45-7.04)$ in patients with SBP to $5.43(95 \% \mathrm{Cl}: 3.68-7.99)$ in patients with MBP. The d1qPELOD-2 was also a significant prognostic factor (table 3). The AUC of the d1qPELOD-2 was $0.82(95 \% \mathrm{Cl}$ : 0.76-0.87) either with SBP or MBP; after correction for the optimism bias, the AUC (and $95 \% \mathrm{Cl}$ ) were strictly identical. The calibration $\mathrm{p}$ values were equal to 0.89 and 0.72 with SBP and MBP respectively. The d1qPELOD-2 with SBP was $0.81(95 \% \mathrm{Cl}, 0.75-0.87)$ in children less than one year of age and $0.81(95 \% \mathrm{Cl}, 0.71-0.92)$ in those between 1 to 12 years. The d1qPELOD-2 with MBP was $0.80(95 \% \mathrm{Cl}, 0.74-0.87)$ in children less than one year of age and 0.82 $(95 \% \mathrm{Cl}, 0.72-0.93)$ in those between 1 to 12 years. For these two scores, the AUC could not be determined for children of more than 12 years of age because of the small sample size. Mortality according to d1qPELOD-2 is given in table 4 . In brief, a d1qPELOD-2 score $\geq 2$ was associated with a mortality rate of $19.8 \%$ or more with d1qPELOD-2 SBP and 15.9\% or more with d1qPELOD-2 MBP. Among deceased, $66.7 \%$ (Se) had 2 or more d1qPELOD-2 SBP points and $85.3 \%$ (Sp) of survivors had less than 2 d1qPELOD-2 SBP points (Ppv: 25.3\%; Npv: 97.2\%). Among deceased $75.0 \%$ (Se) had 2 or more d1qPELOD-2 MBP points and 79.1\% (Sp) of survivors had less than 2 d1qPELOD-2 MBP points (Ppv: 21.1\%; Npv: 97.7\%). Discussion. In our patients with suspected infection and in those with associated shock the predictive validity for PICU mortality of d1PELOD-2 was excellent. Moreover, in 
comparison with what was reported by Seymour et al. in critically ill adults for the qSOFA (AUC=0.66; 95\%Cl: 0.64-0.68), the d1qPELOD-2 had a good predictive validity for PICU mortality (AUC=0.82; 95\%Cl: 0.76-0.87) (10).

Our patients had a median d1PELOD-2 of 3 (IQR: 2-6), suggesting a moderate severity, while those with shock had a median d1PELOD-2 between 9.5 (IQR: 5-13) (patients with low MBP and hyperlactatemia) and 11 (IQR: 6-15) (patients with low SBP and hyperlactatemie (table 3). The mean PIM2 probability of death of the whole population was $6.2 \%$, close to that reported by Schlapbach et al. (between 4.1 and $5.4 \%$ in children with invasive infection) (15). This moderate severity is probably explained by the definition we used (physician diagnosis) like in the study by Weiss et al. (6) who reported that sepsis cases diagnosed by physicians are less severely ill (8). Several studies have reported a moderate level of agreement in the septic children diagnosed by physicians (clinical criteria), 2005 international consensus guidelines (research criteria) and international classification of diseases (administrative criteria): approximately one third of patients with sepsis diagnosed on clinical criteria would not have been included in studies on sepsis diagnosed on research criteria $(6,8)$.

In 2014, the European Society of Intensive Care Medicine and the Society of Critical care Medicine convened a task force who recommended for adults that: (1) sepsis should be defined as life-threatening organ dysfunction caused by a dysregulated host response to infection; (2) for clinical operationalization, organ dysfunction can be represented by an increase in the SOFA score of 2 points or more. The task force also proposed for out-of-hospital adult patients the qSOFA as a new bedside clinical score to rapidly identify the risk of poor outcomes typical of sepsis (13). In children, the PELOD score, proposed in 2003 (12), has been updated in 2013 (PELOD-2) 
(11). Using its first version, we demonstrated that hazard ratio of death significantly increased with the severity of organ dysfunction, as estimated by the PELOD score, and the worst diagnostic category of septic state (16).

A recent study compared children managed with severe sepsis in European and the United States PICUs to identify geographic variation, which may improve the design of future international studies (3). As there were no significant differences in morbidity and mortality between regions after adjusting for several factors the authors suggested that future international clinical trials should use physiologic and laboratory criteria for severe sepsis to establish study eligibility without the requirement for PICU admission (3). In this approach, the PELOD-2 could represent the precise physiologic and laboratory criteria used to identify pediatric sepsis. Similarly to what was observed in adult patients with suspected infection, i.e. a SOFA $\geq 2$ reflects a mortality risk greater than $10 \%$ and can represent organ dysfunction (13), a d1PELOD-2 $\geq 8$ reflected a mortality risk of approximately $10 \%$ or more in our children with suspected infection. This cutoff could, thus, be used to identify organ dysfunction in our PICU patients with suspected infection.

In this study we defined hypotension as low SBP or low MBP either for identifying children with suspected infection and shock and for constructing the qPELOD-2 score. In fact, if MBP is used for initial resuscitation as recommended by the Surviving Sepsis Campaign $(5,13,17)$, SBP is used in the pediatric track and trigger systems as reviewed by Chapman et al. (18).

Our study has some limitations. First, our database is almost 10 years old, and mortality should have improved due to changes in treatments; however, studies conducted on more recent database reported that the PELOD-2 score remains reflective of outcome $(19,20)$. Second, as mentioned above, we did not screen our 
data base with sepsis defined on the basis of 2005 International Sepsis Consensus Conference (4); however, the sensitivity of SIRS criteria has been criticized because they miss patients with infection and organ failure $(6,8,21)$. Third, our dataset included a small number of children over the age of 12 years (9.7\%). Fourth, we did not use volume resuscitation in our definition of shock because this data was not available. Fifth, we only included children admitted in PICU and thus, we did not consider children from different phases of acute care (out of hospital, emergency department, hospital ward). Finally, we did not analyze different types of infection (community and nosocomial). These limitations reduce the generalizability of our findings and emphasize the need for future prospective multicenter studies. Conclusion.

Among children admitted to PICU with suspected infection, PELOD-2 of the first 24hour period after admission was highly predictive of PICU mortality suggesting its use in clinical criteria for sepsis. This could help to standardize definitions and diagnostic criteria of pediatric sepsis. Further studies in other cohorts from different countries and including more patients, are needed to confirm these results. Prospective studies will have also to determine the usefulness of the d1qPELOD-2 in children with suspected infection outside of the PICU or at admission.

S Leteurtre, A Duhamel and $\mathrm{V}$ Deken have full access to all of the data in the study and take responsibility for the integrity of the data and the accuracy of the data analysis. 


\section{References.}

1. Liu V, Escobar GJ, Greene JD, et al. Hospital deaths in patients with sepsis from 2 independent cohorts. JAMA 2014;312:90-92.

2. Ruth A, McCracken CE, Fortenberry JD, et al. Pediatric severe sepsis: current trends and outcomes from the Pediatric Health Information Systems database. Pediatr Crit Care Med 2014;15:828-838.

3. Giuliano JS, Jr., Markovitz BP, Brierley J, et al. Comparison of Pediatric Severe Sepsis Managed in U.S. and European ICUs. Pediatr Crit Care Med 2016;17:522-530. 4. Goldstein B, Giroir B, Randolph A. International pediatric sepsis consensus conference: definitions for sepsis and organ dysfunction in pediatrics. Pediatr Crit Care Med 2005;6:2-8.

5. Brierley J, Carcillo JA, Choong K, et al. Clinical practice parameters for hemodynamic support of pediatric and neonatal septic shock: 2007 update from the American College of Critical Care Medicine. Crit Care Med 2009;37:666-688.

6. Weiss SL, Parker B, Bullock ME, et al. Defining pediatric sepsis by different criteria: discrepancies in populations and implications for clinical practice. Pediatr Crit Care Med 2012;13:e219-226.

7. Balamuth F, Weiss SL, Neuman MI, et al. Pediatric severe sepsis in U.S. children's hospitals. Pediatr Crit Care Med 2014;15:798-805.

8. Weiss SL, Fitzgerald JC, Maffei FA, et al. Discordant identification of pediatric severe sepsis by research and clinical definitions in the SPROUT international point prevalence study. Crit Care 2015;19:325.

9. Shankar-Hari M, Phillips GS, Levy ML, et al. Developing a New Definition and Assessing New Clinical Criteria for Septic Shock: For the Third International Consensus Definitions for Sepsis and Septic Shock (Sepsis-3). JAMA 2016;315:775-787.

10. Seymour CW, Liu VX, Iwashyna TJ, et al. Assessment of Clinical Criteria for Sepsis: For the Third International Consensus Definitions for Sepsis and Septic Shock (Sepsis-3). JAMA 2016;315:762-774.

11. Leteurtre S, Duhamel A, Salleron J, et al. PELOD-2: an update of the PEdiatric logistic organ dysfunction score. Crit Care Med 2013;41:1761-1773.

12. Leteurtre S, Martinot A, Duhamel A, et al. Validation of the paediatric logistic organ dysfunction (PELOD) score: prospective, observational, multicentre study. Lancet 2003;362:192-197.

13. Singer M, Deutschman CS, Seymour CW, et al. The Third International Consensus Definitions for Sepsis and Septic Shock (Sepsis-3). JAMA 2016;315:801-810.

14. Scott HF, Deakyne SJ, Woods JM, et al. The prevalence and diagnostic utility of systemic inflammatory response syndrome vital signs in a pediatric emergency department. Acad Emerg Med 2015;22:381-389.

15. Schlapbach LJ, Straney L, Alexander J, et al. Mortality related to invasive infections, sepsis, and septic shock in critically ill children in Australia and New Zealand, 2002-13: a multicentre retrospective cohort study. Lancet Infect Dis 2015;15:46-54.

16. Leclerc F, Leteurtre S, Duhamel A, et al. Cumulative influence of organ dysfunctions and septic state on mortality of critically ill children. Am J Respir Crit Care Med 2005;171:348-353.

17. Dellinger RP, Levy MM, Rhodes A, et al. Surviving Sepsis Campaign: international guidelines for management of severe sepsis and septic shock, 2012. Intensive Care Med 2013;39:165-228.

18. Chapman SM, Wray J, Oulton K, et al. Systematic review of paediatric track and trigger systems for hospitalised children. Resuscitation 2016. 
19. Goncalves JP, Severo M, Rocha C, et al. Performance of PRISM III and PELOD-2 scores in a pediatric intensive care unit. Eur J Pediatr 2015;174:1305-1310.

20. Morin L, Ray S, Wilson C, et al. Refractory septic shock in children: a European Society of Paediatric and Neonatal Intensive Care definition. Intensive Care Med 2016;42:1948-1957.

21. Kaukonen KM, Bailey M, Pilcher D, et al. Systemic inflammatory response syndrome criteria in defining severe sepsis. N Engl J Med 2015;372:1629-1638. 
Table 1. Quick PELOD-2 (qPELOD-2) criteria

\begin{tabular}{|c|c|c|c|c|c|}
\hline \multirow[t]{2}{*}{ Criteria } & Altered mentation & \multicolumn{3}{|c|}{ Hypotension } & Tachycardia \\
\hline & \multirow[t]{7}{*}{ Glasgow coma score $<11$} & \multicolumn{3}{|c|}{$\mathrm{SBP}^{1}(\mathrm{~mm} \mathrm{Hg})$ or $\mathrm{MBP}^{2}(\mathrm{~mm} \mathrm{Hg})$} & \\
\hline & & $<1$ month & $<65$ & $<46$ & $<12$ years $>195$ \\
\hline & & 1-11 months & $<75$ & $<55$ & $\geq 12$ years $>150$ \\
\hline & & $12-23$ months & $<85$ & $<60$ & \\
\hline & & 24-59 months & $<85$ & $<62$ & \\
\hline & & $60-143$ months & $<85$ & $<65$ & \\
\hline & & $\geq 144$ months & $<95$ & $<67$ & \\
\hline Score & Absent: $0 /$ Present: 1 & \multicolumn{3}{|c|}{ Absent: 0/ Present: 1} & Absent: 0/ Present: 1 \\
\hline
\end{tabular}

Abbreviations: PELOD: PEdiatric Logistic Organ Dysfunction; SBP, systolic blood pressure; MBP, mean blood pressure.

${ }^{1}$ Adapted from Leteurtre et al. (12); ${ }^{2}$ Adapted from Leteurtre et al. (11). 
Table 2. Population characteristics.

\begin{tabular}{|c|c|}
\hline Patients with suspected infection (primary disease at entry) & $\mathrm{N}=862$ \\
\hline \multicolumn{2}{|l|}{ Baseline characteristics } \\
\hline Gender (male), n (\%) & $468(54.3)$ \\
\hline Age, months, median [IQR] & $12.3[2.1 ; 55.7]$ \\
\hline 0 to $<1, \mathrm{n}(\%)$ & $105(12.2)$ \\
\hline 1 to $11, \mathrm{n}(\%)$ & $320(37.1)$ \\
\hline 12 to $23, \mathrm{n}(\%)$ & $93(10.8)$ \\
\hline 24 to $59, \mathrm{n}(\%)$ & $137(15.9)$ \\
\hline 60 to $143, \mathrm{n}(\%)$ & $123(14.3)$ \\
\hline$\geq 144, \mathrm{n}(\%)$ & $84(9.7)$ \\
\hline PIM2 score (predicted death rate in \%) median, [IQR], mean & $1.2[0.7 ; 3.9], 6.2$ \\
\hline \multicolumn{2}{|l|}{ Primary reason for PICU admission n (\%) } \\
\hline Respiratory & $487(56.5)$ \\
\hline Neurological & $118(13.7)$ \\
\hline Cardiovascular & $152(17.6)$ \\
\hline Hepatic & 0 \\
\hline Genitourinary & $16(1.9)$ \\
\hline Gastrointestinal & $42(4.9)$ \\
\hline Endocrine & 0 \\
\hline Musculoskeletal & $2(0.2)$ \\
\hline Hematological & $8(0.9)$ \\
\hline Miscellaneous/undetermined & $26(3.0)$ \\
\hline Mixed & $11(1.3)$ \\
\hline \multicolumn{2}{|l|}{ Outcomes } \\
\hline Mechanical ventilation, n (\%) & $338(39.2)$ \\
\hline Length of ICU stay, days; median, (IQR) & $4[2 ; 7]$ \\
\hline Mortality, n (\%) & $60(7.0)$ \\
\hline
\end{tabular}


Table 3. Description and odds ratios of death of PELOD-2 and qPELOD-2 scores on day 1 among children with suspected infection

\begin{tabular}{|c|c|c|c|c|c|}
\hline Score & n (t) & Median & IQR & $\begin{array}{l}\text { Odds } \\
\text { Ratio }\end{array}$ & $95 \% \mathrm{Cl}$ \\
\hline PELOD-2 & $862(60)$ & 3 & $2-6$ & 1.50 & $1.39-1.63$ \\
\hline $\begin{array}{l}\text { PELOD-2 in those with low SBP } \\
\text { and hyperlactatemia (> } 2 \mathrm{mmol} / \mathrm{L})\end{array}$ & $69(23)$ & 11 & $6-15$ & 1.39 & $1.19-1.62$ \\
\hline $\begin{array}{l}\text { PELOD-2 in those with low MBP } \\
\text { and hyperlactatemia (>2 mmol// }{ }^{\circ}\end{array}$ & $88(27)$ & 9.5 & $5-13$ & 1.49 & $1.26-1.77$ \\
\hline qPELOD-2 (SBP) & $862(60)$ & 1 & $0-1$ & 4.93 & $3.45-7.04$ \\
\hline qPELOD-2 (MBP) & $862(60)$ & 1 & $0-1$ & 5.43 & $3.68-7.99$ \\
\hline
\end{tabular}

Abbreviations: qPELOD-2, quick PEdiatric Logistic Organ Dysfunction 2; IQR, interquartile range; SBP, systolic blood pressure; MBP, mean blood pressure; $\dagger$, death. 
Table 4. Mortality rate according to qPELOD-2 on day 1.

\begin{tabular}{ccc}
\hline q PELOD-2 SBP (score) & Patients (n) & Death (\%) \\
0 & 330 & 0.9 \\
1 & 374 & 4.5 \\
2 & 131 & 19.8 \\
3 & 27 & 51.8 \\
\hline & & \\
\hline q PELOD-2 MBP (score) & Patients (n) & Death (\%) \\
0 & 249 & 0.8 \\
1 & 400 & 3.25 \\
2 & 182 & 15.9 \\
3 & 31 & 51.6 \\
\hline
\end{tabular}

Abbreviations: qPELOD-2, quick PEdiatric Logistic Organ Dysfunction 2; $\mathrm{SBP}$, systolic blood pressure; MBP, mean blood pressure. 
SUPPLEMENTAL CONTENT

Table I: Contribution to sepsis mortality of each variable selected in the Pediatric Logistic Organ Dysfunction (PELOD)-2 score on the population of 862 children admitted to PICU with suspected infection.

\begin{tabular}{|c|c|c|c|}
\hline $\begin{array}{c}\text { Type of Variables } \\
\text { and Cutoffs }\end{array}$ & Odds ratio $(95 \% \mathrm{Cl})$ & $\mathrm{p}$ & $\begin{array}{l}\text { PELOD-2 } \\
\text { points }\end{array}$ \\
\hline \multicolumn{4}{|l|}{ Glasgow coma score } \\
\hline$\geq 11$ & 1 & & \\
\hline $5-10$ & $1.11(0.39-3.19)$ & 0.8422 & 1 \\
\hline $3-4$ & $11.01(2.41-50.31)$ & 0.0020 & 4 \\
\hline \multicolumn{4}{|l|}{ Pupillary reaction } \\
\hline Both reactive & 1 & & \\
\hline Both fixed & $6.13(1.38-27.23)$ & 0.0171 & 5 \\
\hline \multicolumn{4}{|l|}{ Lactatemia } \\
\hline$<5.0 \mathrm{mmol} / \mathrm{L}$ & 1 & & \\
\hline $5.0-10.9, \mathrm{mmol} / \mathrm{L}$ & $1.11(0.34-3.67)$ & 0.8613 & 1 \\
\hline$\geq 11.0 \mathrm{mmol} / \mathrm{L}$ & $1.85(0.31-10.93)$ & 0.4952 & 4 \\
\hline \multicolumn{4}{|c|}{ Mean arterial pressure $(\mathrm{mm} \mathrm{Hg})$} \\
\hline Cutoff 3 & 1 & & \\
\hline Cutoff 2-cutoff 3 & $0.53(0.19-1.47)$ & 0.2231 & 2 \\
\hline Cutoff 1-cutoff 2 & $1.93(0.69-5.41)$ & 0.2084 & 3 \\
\hline$<$ Cutoff 1 & $9.12(1.42-58.59)$ & 0.0198 & 6 \\
\hline \multicolumn{4}{|l|}{ Creatinine $(\mu \mathrm{mol} / \mathrm{L})$} \\
\hline$<$ Cutoff 1 & 1 & & \\
\hline$\geq$ Cutoff 1 & $2.56(1.10-5.96)$ & 0.0288 & 2 \\
\hline \multicolumn{4}{|l|}{$\mathrm{PaO}_{2}(\mathrm{mmHg}) / \mathrm{FIO}_{2}$ ratio } \\
\hline$\geq 61$ & 1 & & \\
\hline$\leq 60$ & $2.96(0.73-11.99)$ & 0.1289 & 2 \\
\hline \multicolumn{4}{|l|}{$\mathrm{PaCO}_{2}(\mathrm{mmHg})$} \\
\hline$\leq 58$ & 1 & & \\
\hline $59-95$ & $1.11(0.42-2.98)$ & 0.8293 & 1 \\
\hline$\geq 95$ & $3.43(0.35-33.92)$ & 0.2925 & 3 \\
\hline \multicolumn{4}{|l|}{ Ventilation } \\
\hline No or noninvasive & 1 & & \\
\hline Invasive & $5.37(2.03-14.22)$ & 0.0007 & 3 \\
\hline \multicolumn{4}{|c|}{ White blood cell count $\left(\times 10^{9} / \mathrm{L}\right)$} \\
\hline$>2$ & 1 & & \\
\hline$\leq 2$ & $9.48(3.15-28.53)$ & $<0.0001$ & 2 \\
\hline \multicolumn{4}{|l|}{ Platelets $\left(\times 10^{9} / \mathrm{L}\right)$} \\
\hline$\geq 142$ & 1 & & \\
\hline $77-141$ & $3.82(1.27-11.46)$ & 0.0170 & 1 \\
\hline$\leq 76$ & $2.97(1.12-7.87)$ & 0.0282 & 2 \\
\hline
\end{tabular}

